\title{
Clinical Pharmacokinetics and Pharmacodynamics of Lenalidomide
}

\author{
Nianhang Chen $^{1} \cdot \operatorname{Simon}$ Zhou $^{1} \cdot$ Maria Palmisano $^{1}$
}

Published online: 28 June 2016

(C) The Author(s) 2016. This article is published with open access at Springerlink.com

\begin{abstract}
Lenalidomide is a lead therapeutic in multiple myeloma and deletion 5q myelodysplastic syndromes and shows promising activities in other hematologic malignancies. This article presents a comprehensive review of the clinical pharmacokinetics and pharmacodynamics of lenalidomide. Oral lenalidomide is rapidly and highly absorbed ( $>90 \%$ of dose) under fasting conditions. Food affects oral absorption, reducing area under the concentration-time curve (AUC) by $20 \%$ and maximum concentration $\left(C_{\max }\right)$ by $50 \%$. The increase in AUC and $C_{\max }$ is dose proportional, and interindividual variability in plasma exposure is low to moderate. Lenalidomide distributes into semen but is undetectable 3 days after stopping treatment. Biotransformation of lenalidomide in humans includes chiral inversion, trivial hydroxylation, and slow non-enzymatic hydrolysis. Approximately $82 \%$ of an oral dose is excreted as lenalidomide in urine within $24 \mathrm{~h}$. Lenalidomide has a short half-life $(3-4 \mathrm{~h})$ and does not accumulate in plasma upon repeated dosing. Its pharmacokinetics are consistent across patient populations, regardless of the type of hematologic malignancy. Renal function is the only important factor affecting lenalidomide plasma exposure. Lenalidomide has no QT prolongation risk at approved doses, and higher plasma exposure to lenalidomide is associated with increased risk of neutropenia and thrombocytopenia. Despite being a weak substrate of P-glycoprotein (P-gp) in vitro, lenalidomide does not have clinically significant pharmacokinetic interactions with $\mathrm{P}-\mathrm{gp}$ substrates/inhibitors in controlled
\end{abstract}

Nianhang Chen

nchen@celgene.com

1 Department of Clinical Pharmacology, Celgene Corporation, 86 Morris Avenue, Summit, NJ 07901, USA studies. The AUC-matched dose adjustment is recommended for patients with renal impairment at the start of therapy. No dose adjustment for lenalidomide is needed on the basis of age, ethnicity, mild hepatic impairment, or drug-drug interactions.

\section{Key Points}

Lenalidomide represents the standard of care for treating multiple myeloma and deletion $5 \mathrm{q}$ myelodysplastic syndromes.

This is a review of the pharmacokinetics, pharmacodynamics, exposure-response relationships, and assessment of potential drug-drug interactions of lenalidomide in various hematologic malignancies.

The starting dose of lenalidomide must be adjusted according to renal function.

\section{Introduction}

Lenalidomide is a chemical analog of thalidomide, with antineoplastic, antiangiogenic, pro-erythropoietic, and immunomodulatory properties [1-3]. It binds to an E3 ubiquitin ligase complex protein, cereblon, modulating its downstream effects [4-6]. This interaction was shown to be associated with antitumor and immunomodulatory properties of lenalidomide $[3,6,7]$.

Clinical efficacy has been demonstrated for lenalidomide in the treatment of hematologic malignancies [8-13]. 
It is approved in combination with dexamethasone for the treatment of multiple myeloma (MM) and as monotherapy for the treatment of transfusion-dependent anemia due to myelodysplastic syndromes (MDS) associated with deletion $5 \mathrm{q}$ and relapsed or refractory mantle cell lymphoma (MCL). Combinations of lenalidomide with small molecule chemotherapies and novel biologic agents are being explored in clinical trials, with several recent approvals in the treatment of relapsed or refractory MM [14-20].

Lenalidomide has a predictable tolerability profile and lacks the neurological side effects of thalidomide, including sedation and neuropathy, allowing long-term administration [2, 21, 22]. Primary adverse events (AEs) are neutropenia and thrombocytopenia. Some AEs of lenalidomide are more often associated with a specific disease. For example, venous thromboembolic events are observed more frequently in patients with MM receiving lenalidomide/dexamethasone therapy, while tumor lysis syndrome and tumor flare reaction are observed more frequently in patients with chronic lymphocytic leukemia (CLL) [2, 21, 22].

The recommended dose of lenalidomide is disease specific, and the approved starting dose is lower for MDS (10 mg/day) than for MM and MCL ( $25 \mathrm{mg} /$ day) [23]. The use of very low starting doses $(2.5 \mathrm{or} 5 \mathrm{mg}$ ) of lenalidomide followed by stepwise dose escalation is common in clinical studies with CLL to minimize the risk of tumor lysis syndrome and tumor flare [21, 24]. Importantly, the starting dose should be adjusted according to renal function regardless of indication [23]. Furthermore, proper dose modifications are recommended to manage toxicities [23].

This article aims to review the available clinical data on pharmacokinetics, pharmacodynamics, exposure-response relationships and drug-drug interactions of lenalidomide in various populations. This knowledge will assist clinicians with rational dosage decisions.

\section{Formulations}

Lenalidomide contains an asymmetric carbon atom and is produced as a 50:50 racemic mixture of the optically active forms of lenalidomide, $S$ - and $R$-enantiomers [23]. Commercial lenalidomide products are available in the US and EU as Revlimid ${ }^{\circledR}$ hard gelatin capsules for oral administration, with seven strengths: $2.5,5,7.5,10,15,20$, and $25 \mathrm{mg}[23,25]$. All capsule formulations are interchangeable for a given dose based on the results from bioequivalence studies (Celgene, data on file).

Patients with dysphagia, such as the elderly and children, have difficulty swallowing capsules. A lenalidomide suspension formulation for these patients is currently available in clinical studies. Because lenalidomide is a teratogenic drug [23], opening of lenalidomide capsules and extemporaneous compounding of lenalidomide suspension or solution is not recommended. A method was reported for tube administration of lenalidomide, in which capsules were disintegrated in hot water to form a suspension without grinding or opening them [26]. Lenalidomide was found to be stable in hot water at $55{ }^{\circ} \mathrm{C}$ for $24 \mathrm{~h}$ in the prepared suspension and was not adsorbed onto the percutaneous endoscopic gastrostomy tube [26]. However, it remains unknown whether tube feeding of such heated lenalidomide suspension would achieve drug plasma exposure similar to that of oral administration of capsules or suspension.

\section{Pharmacokinetics in Healthy Adults}

\subsection{Absorption}

In healthy adults, lenalidomide is rapidly absorbed under fasting conditions, with the maximum concentration $\left(C_{\max }\right)$ in plasma observed at $1 \mathrm{~h}$ postdose [27]. Greater than $90 \%$ of a dose of lenalidomide is estimated to be absorbed into blood [28]. Consistent with the high bioavailability, the oral bioavailability of lenalidomide is similar between commercial capsules and an experimental oral suspension, with mean values of both $C_{\max }$ and area under the concentration-time curve (AUC) comparable between the two formulations (Table 1). Lenalidomide $C_{\max }$ and AUC increase proportionally with increases in dose from 5 to $400 \mathrm{mg}$ [27]. The interindividual variability for lenalidomide plasma exposure parameters is low to moderate in well-controlled studies in healthy volunteers: approximately $20 \%$ for AUC and $30 \%$ for $C_{\max }$ [29]. Coadministration with a high-fat meal reduces the extent and rate of lenalidomide oral absorption, resulting in an approximate $20 \%$ decrease in AUC, $50 \%$ decrease in $C_{\max }$, and 1.6-h delay in the time to reach $C_{\max }\left(T_{\max }\right)$ [27].

\subsection{Distribution}

The ex vivo binding of lenalidomide to plasma proteins is low: approximately $40 \%$ in healthy volunteers [30]. The percentage of radioactivity estimated to distribute into red blood cells (36-44\%) approximates the mean hematocrit value $(42-43 \%)$ following a $\left[{ }^{14} \mathrm{C}\right]$-lenalidomide dose, suggesting that lenalidomide, the primary radioactive component in circulation, is distributed similarly between cellular and plasma components of whole blood [28]. Thus, plasma is a suitable matrix for the representation of lenalidomide concentrations in whole blood. Apparent volume of distribution of lenalidomide often ranges from approximately 74-91 L in young healthy volunteers [27], 
Table 1 Plasma

pharmacokinetic parameters of lenalidomide in healthy American volunteers

\begin{tabular}{|c|c|c|c|}
\hline & \multicolumn{2}{|c|}{ Capsule (25 mg) } & \multirow{2}{*}{$\begin{array}{l}\text { Suspension }(25 \mathrm{mg}) \\
\text { Young adults }\end{array}$} \\
\hline & Young adults & Older adults & \\
\hline Age (years) & $27-38$ & 58 & 30 \\
\hline$T_{\max }(\mathrm{h})$ & 0.75 & 1 & 1 \\
\hline$C_{\max }(\mathrm{ng} / \mathrm{mL})$ & 390 & 568 & 413 \\
\hline $\operatorname{AUC}_{\infty}(\mathrm{h} \mathrm{ng} / \mathrm{mL})$ & 1369 & 2091 & 1319 \\
\hline $\mathrm{CL} / F(\mathrm{~mL} / \mathrm{min})$ & 301 & 199 & 318 \\
\hline$V_{\mathrm{z}} / F(\mathrm{~L})$ & 74 & 56 & 76 \\
\hline$t_{1 / 2}(\mathrm{~h})$ & 2.8 & 3.3 & 2.8 \\
\hline $\mathrm{Fe}(\%$ of dose $)$ & $74-81$ & 84 & 82 \\
\hline $\mathrm{CL}_{\mathrm{R}}(\mathrm{mL} / \mathrm{min})$ & $227-251$ & 159 & $259^{\mathrm{a}}$ \\
\hline References & {$[27,33]$} & [30] & [28] \\
\hline
\end{tabular}

Data are expressed as mean for age, median for $T_{\max }$, and arithmetic or geometric mean for the remaining pharmacokinetic parameters

$A U C_{\infty}$ area under the plasma concentration-time curve from time zero to infinity, $C L / F$ apparent total clearance, $C L_{R}$ renal clearance, $C_{\max }$ maximum concentration, $\mathrm{Fe}$ excreted in urine as unchanged drug over $24 \mathrm{~h}, t_{1 / 2}$ terminal half-life, $T_{\max }$ time to reach $C_{\max }, V_{z} / F$ apparent volume of distribution based on the terminal phase

${ }^{\text {a }}$ Derived from dose, $\mathrm{AUC}_{\infty}$, and $\mathrm{Fe}$ which is greater than the volume of total body water $(42 \mathrm{~L})$ after accounting for the good bioavailability ( $>90 \%$ ), suggesting moderate extravascular distribution of the drug.

Because lenalidomide is a teratogenic drug, the possible consequence of embryo-fetal exposure, absorbed from ejaculate in females of childbearing potential through transmission in semen from treated males is of concern. A study was conducted in healthy males to evaluate the distribution of lenalidomide in semen [31]. Each participant received lenalidomide $25 \mathrm{mg}$ for 4 days and provided a single semen sample at the assigned time $(2,24,72$, or $168 \mathrm{~h})$ after the last dose. The mean lenalidomide concentration in semen was higher than the time-matched concentration in plasma 2 and $24 \mathrm{~h}$ postdose (478 vs. 219 and $10 \mathrm{ng} / \mathrm{mL}$ vs. undetectable, respectively). However, the total amount of drug presented in semen over $72 \mathrm{~h}$ was very minor $(<0.01 \%$ of the dose). In addition, lenalidomide was not detected in semen 3 days after the last dose, defining the starting day for 'drug-free' semen in healthy males. As a precaution, males must use condoms during sexual contact with females of reproductive potential while taking lenalidomide and for up to 28 days after discontinuing lenalidomide.

\subsection{Biotransformation and Metabolism}

Lenalidomide undergoes rapid chiral inversion, with $S$-lenalidomide as the preferred form in humans [27]. The $R /$ $S$ plasma concentration ratio stabilized within the first hour of a racemic lenalidomide dose; $R$ - and S-enantiomers averaged approximately 45 and $55 \%$ of the total circulating drug [27].
In vitro studies have demonstrated that lenalidomide is not a substrate of human cytochrome P450 (CYP) enzymes and is not subjected to direct conjugative metabolism [32]. Lenalidomide is broken down slowly through non-enzymatic hydrolysis in aqueous solutions and in hepatocytes at physiological $\mathrm{pH}$, due to the hydrolytic cleavage of lenalidomide's glutarimide ring. Hydrolysis of lenalidomide also occurs in human plasma, with an in vitro half-life of approximately $8 \mathrm{~h} \mathrm{[32].}$

Consistent with the above in vitro results, a clinical study using $\left[{ }^{14} \mathrm{C}\right]$-lenalidomide concluded that metabolism contributes, to a very minor extent, to the clearance of lenalidomide in humans [28]. The unchanged lenalidomide was the predominant component (92\%) of the circulating radioactivity. The remaining radioactivity consisted primarily of two metabolites: 5-hydroxylenalidomide and $\mathrm{N}$ acetyl-lenalidomide, resulting from hydroxylation of the amino-iso-indolinone moiety and $\mathrm{N}$-acetylation, respectively; each constituted $<5 \%$ of parent levels in circulation. Neither metabolite is expected to contribute to the therapeutic activity of lenalidomide based on the results from in vitro pharmacological assays.

\subsection{Excretion and Elimination}

Provided as capsules for oral administration, lenalidomide is eliminated predominantly through renal excretion of the unchanged drug. In an early dose-ranging study, $65-68 \%$ of the administered dose was found as the unchanged drug in urine [27]. In more recent studies, approximately $80 \%$ of the administered dose was consistently found in urine as unchanged drug [30, 33]. Most of the drug was excreted into urine 
within the first $8 \mathrm{~h}$ postdose, and urinary excretion was nearly complete by $12 \mathrm{~h}$ postdose (Fig. 1). Mean renal clearance was approximately $\geq 200 \mathrm{~mL} / \mathrm{min}$ in young healthy volunteers $[27,33]$, exceeding the expected rate at which the unbound lenalidomide is filtered through the kidneys [27]. Thus, renal excretion of lenalidomide is likely to involve active and passive processes. However, lenalidomide renal excretion was not saturable over an 80-fold variation in dose (5-400 mg) [27].

Provided as an oral suspension of $\left[{ }^{14} \mathrm{C}\right]$-lenalidomide $(25 \mathrm{mg})$, total recovery of the $\left[{ }^{14} \mathrm{C}\right]$-radioactivity from excreta averaged $94.3 \%$ of the administered dose, with mean contributions of 90 and $4 \%$ from urine and feces, respectively [28]. The excretion was rapid, as demonstrated by a majority ( $88 \%$ ) of the radioactivity being recovered within $24 \mathrm{~h}$ postdose. Approximately $82 \%$ of the radioactive dose was excreted as lenalidomide, almost exclusively via the urinary route within the first $24 \mathrm{~h}$, which is consistent with the findings for capsule formulations.

Because of the rapid renal excretion of lenalidomide, the plasma half-life of lenalidomide is short-generally $3 \mathrm{~h}$ (Table 1). As a result, lenalidomide plasma exposure does not accumulate upon repeated doses. In young healthy adults, total apparent clearance of lenalidomide is approximately $300 \mathrm{~mL} / \mathrm{min}$, with $80 \%$ accounted for by renal clearance and $20 \%$ by non-renal clearance [33]. Lenalidomide clearance tends to be lower in older healthy adults, although renal excretion of lenalidomide is not affected [30].

\section{Pharmacokinetics in Patients with Hematologic Malignancies}

The pharmacokinetics of lenalidomide have been investigated in patients with various types of hematologic malignancies, including MM, MDS, MCL, CLL, acute

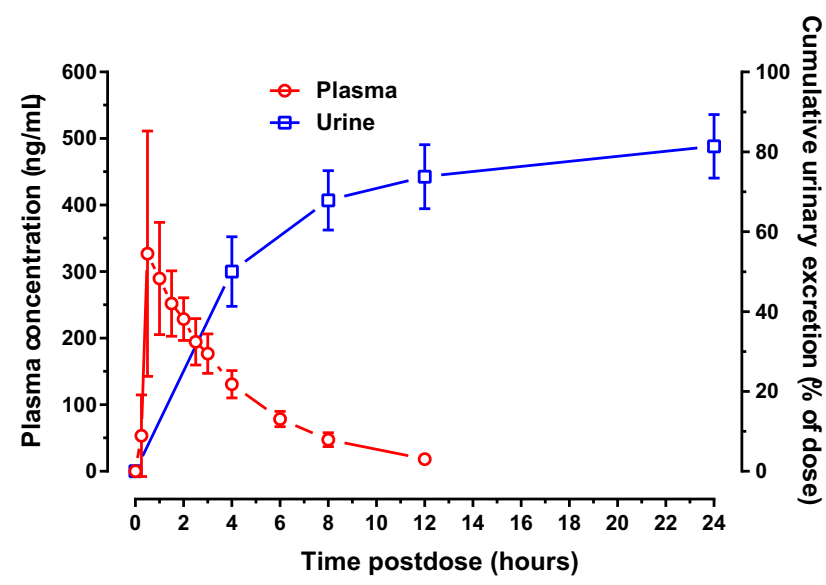

Fig. 1 Representative plasma concentration-time and urine excretion-time profiles of lenalidomide in healthy volunteers. Data are shown as mean \pm standard deviation. Adapted from Chen et al. [33] myeloid leukemia (AML), adult T-cell leukemia/lymphoma, and peripheral T-cell lymphoma [34-42]. Most of these diseases commonly occur later in life, at a time when renal function is diminishing. In general, pharmacokinetic studies for these diseases have included patients with mild renal impairment $(\mathrm{RI})$ but excluded those with moderate to severe RI. Lenalidomide pharmacokinetics were similar across patient populations in these studies, regardless of the type of hematologic malignancy (Table 2). As observed in healthy volunteers, lenalidomide displayed rapid absorption and elimination in patients, often with a median $T_{\max }$ of $1 \mathrm{~h}$ under fasting conditions and a mean half-life of 3-4 h. The median $T_{\max }$ was longer in studies in which food, which delays drug absorption, was not restricted prior to dosing [38, 41, 42]. As demonstrated in Table 2, the dose-exposure relationship remained linear across studies, with plasma AUC and $C_{\max }$ proportional to dose from 5 to $50 \mathrm{mg}$. Dose-proportional increases in AUC and $C_{\max }$ were also demonstrated in a study evaluating dose ranges in patients with MM [29].

There were no differences in lenalidomide pharmacokinetics between patients of varying hematologic malignancies and healthy volunteers if they were of advanced age and had similar renal function (Tables 1, 2), except for a slightly high interindividual variability for AUC (25-60\%) [29]. Compared with young healthy volunteers, patients consistently showed lower lenalidomide clearance and thus higher AUC $(+50 \%$ or more) for the same dose (Tables 1,2). The reduced lenalidomide clearance in patients could be partially due to less robust renal function and thus slower excretion of lenalidomide. Interestingly, lenalidomide clearance remained lower even when patients had normal renal excretion of lenalidomide [42]. It is possible that age-related changes in drug disposition other than renal excretion also contributed to the decreased lenalidomide clearance in patients. The lower apparent volume of distribution in patients (Table 2) versus young healthy volunteers (Table 1) could be attributed to decreased clearance because volume of distribution is derived from the ratio of clearance to half-life in conventional pharmacokinetic analyses.

Lenalidomide may have low to moderate central nervous system (CNS) penetration. In a patient with meningeal myeloma, the plasma and cerebrospinal fluid (CSF) concentrations of lenalidomide $1.5 \mathrm{~h}$ (close to plasma $T_{\max }$ ) after a 25-mg dose were 1220 and $125 \mathrm{ng} / \mathrm{mL}$, respectively, resulting in a CSF-to-plasma concentration ratio of 0.1 [43]. The CSF concentration in this patient reached therapeutic range (Table 2). In patients with recurrent/refractory CNS and intraocular lymphoma, lenalidomide was detected in ventricular CSF $(0.6-7.9 \mathrm{ng} / \mathrm{mL})$ in each of four patients $12-15 \mathrm{~h}$ after a $20-\mathrm{mg}$ dose but was detected $(>0.5 \mathrm{ng} / \mathrm{mL})$ in only one of three patients after a $10-\mathrm{mg}$ 
Table 2 Plasma pharmacokinetic parameters of lenalidomide in patients with various hematologic malignancies

\begin{tabular}{|c|c|c|c|c|c|c|c|c|c|}
\hline & \multicolumn{3}{|c|}{$\mathrm{MM}(\mathrm{CrCl} \geq 60 \mathrm{~mL} / \mathrm{min})$} & \multicolumn{2}{|l|}{ MDS } & \multirow{2}{*}{$\begin{array}{l}\mathrm{MCL}^{\mathrm{a}} \\
\text { Americans }\end{array}$} & \multirow{2}{*}{$\begin{array}{l}\text { CLL } \\
\text { Americans }\end{array}$} & \multirow{2}{*}{$\begin{array}{l}\text { AML } \\
\text { Americans }\end{array}$} & \multirow{2}{*}{$\begin{array}{l}\text { ATL/PTCL } \\
\text { Japanese }\end{array}$} \\
\hline & Caucasian & Japanese & Chinese & Americans & Japanese & & & & \\
\hline Dose (mg) & 25 & 25 & 25 & 10 & 10 & 25 & 5 & 50 & 25 \\
\hline$N$ & 34 & 12 & 9 & 12 & 6 & 24 & 11 & 10 & 9 \\
\hline$T_{\max }(\mathrm{h})$ & 1 & 1 & 0.93 & 1 & 2.52 & NA & 1 & 1.91 & 1.48 \\
\hline$C_{\max }(\mathrm{ng} / \mathrm{mL})$ & 487 & 572 & 596 & 179 & 136 & 440 & 85 & 946 & 503 \\
\hline $\operatorname{AUC}(\mathrm{h} \mathrm{ng} / \mathrm{mL})^{\mathrm{b}}$ & 2124 & 2305 & 2202 & 933 & 867 & 2538 & 414 & 5509 & 2472 \\
\hline $\mathrm{CL} / F(\mathrm{~mL} / \mathrm{min})$ & 196 & 181 & 184 & $179^{\mathrm{a}}$ & 190 & 156 & 201 & 168 & 168 \\
\hline$V_{\mathrm{z}} / F(\mathrm{~L})$ & 54 & 42 & 51 & $58^{\mathrm{a}}$ & $54^{\mathrm{a}}$ & 46 & 59 & $54^{\mathrm{c}}$ & 47 \\
\hline$t_{1 / 2}(\mathrm{~h})$ & 3.2 & 2.7 & 3.2 & $3.7^{\mathrm{a}}$ & 3.3 & 3.4 & 3.4 & 4.1 & 3.2 \\
\hline References & [36] & [36] & [36] & {$[29,37]$} & [38] & [39] & [40] & [41] & [42] \\
\hline
\end{tabular}

Data are expressed as median or arithmetic mean for $T_{\max }$ and arithmetic or geometric mean for the remaining pharmacokinetic parameters $A M L$ acute myeloid leukemia, $A T L$ adult T-cell leukemia/lymphoma, $A U C$ area under the plasma concentration-time curve, $A U C_{24} \mathrm{AUC}$ from time zero to $24 \mathrm{~h}, A U C_{\infty}$ AUC from time zero to infinity, $C L / F$ apparent total clearance, $C L L$ chronic lymphocytic leukemia, $C_{\max }$ maximum concentration, $\mathrm{CrCl}$ creatinine clearance, $\mathrm{MCL}$ mantle cell lymphoma, $M D S$ myelodysplastic syndromes, $M M$ multiple myeloma, $N A$ not available, $P T C L$ peripheral T-cell lymphoma, $t_{1 / 2}$ terminal half-life, $T_{\max }$ time to reach $C_{\max }, V_{z} / F$ apparent volume of distribution based on the terminal phase

${ }^{a}$ Data were collected from the referenced study and are on file

b $\mathrm{AUC}_{\infty}$ or $\mathrm{AUC}_{24}$. Values for the two parameters are expected to be similar due to the short half-life of the drug

c Derived from CL/F and $t_{1 / 2}$

dose [44]. Since most of a lenalidomide dose is cleared from the body $12 \mathrm{~h}$ postdose, the CSF concentration is anticipated to be higher if measured at an earlier time point. In line with lenalidomide penetration into CSF, improved CNS symptoms were observed in these patients [43, 44].

\section{Pharmacokinetics in Special Populations}

\subsection{Patients with Renal Impairment}

The effect of RI on lenalidomide pharmacokinetics was first studied in patients with non-malignant conditions [30]. In this study, RI was the result of cardiovascular and/or endocrine disorders. Thirty patients, aged 39-76 years, were stratified into five groups according to baseline creatinine clearance $(\mathrm{CrCl})$, measured by 24 -h urine collection: normal renal function $(\mathrm{CrCl}>80 \mathrm{~mL} / \mathrm{min})$, mild $\mathrm{RI}$ ( $\mathrm{CrCl} 50-80 \mathrm{~mL} / \mathrm{min})$, moderate $\mathrm{RI}(\mathrm{CrCl} 30$ to $<50 \mathrm{~mL} /$ $\mathrm{min})$, severe $\mathrm{RI}(\mathrm{CrCl}<30 \mathrm{~mL} / \mathrm{min})$, and end-stage renal disease (ESRD) requiring dialysis. The mean age of each renal function group (50-68 years) was within the range for target patient populations. All participants received single 25-mg lenalidomide doses regardless of renal function. Mean urinary excretion of unchanged lenalidomide was $84 \%$ of the dose in the normal renal function group and declined to 69,38 , and $43 \%$ in the mild, moderate, and severe RI groups, respectively. With diminishing renal function, total and renal clearances of lenalidomide decreased, while AUC and terminal half-life in plasma increased. The differences in these parameters between normal renal function and mild RI groups $(<32 \%)$ were not statistically significant. In the moderate and severe RI groups, AUC was increased by $200-300 \%$, and half-life was prolonged to approximately $9-10 \mathrm{~h}$. On a non-dialysis day, patients with ESRD had an approximate $400 \%$ increase in AUC, with a long half-life of approximately $16 \mathrm{~h}$. A 4-h hemodialysis session removed $31 \%$ of lenalidomide from the body. However, RI did not alter the absorption (as indicated by $C_{\max }$ and $T_{\max }$ ), protein binding, chiral inversion, or non-renal elimination of lenalidomide. From these findings, adjustments of the lenalidomide starting dose are recommended for patients with $\mathrm{CrCl}<50 \mathrm{~mL} / \mathrm{min}$ [30].

$\mathrm{RI}$ is a common complication in MM, occurring in up to half of patients and at various stages of the disease [45]. To further assess whether the condition of MM may affect lenalidomide exposure, a phase II study was prospectively conducted and validated lenalidomide dose adjustments by evaluating the pharmacokinetics, safety, and efficacy of lenalidomide given with dexamethasone $40 \mathrm{mg}$ weekly in patients with MM and various degrees of stable RI [46]. The study enrolled 38 patients (median age 65 years) with symptomatic MM. These patients were stratified into the same five groups as defined by the study above [30], but the stratification was based on $\mathrm{CrCl}$ estimated using the Cockcroft-Gault formula. The lenalidomide starting dose followed the dosing guidelines derived in that study [30]: $25 \mathrm{mg}$ once daily for normal renal function and mild RI, $10 \mathrm{mg}$ once daily for moderate RI, $15 \mathrm{mg}$ once every other day for severe RI, and 


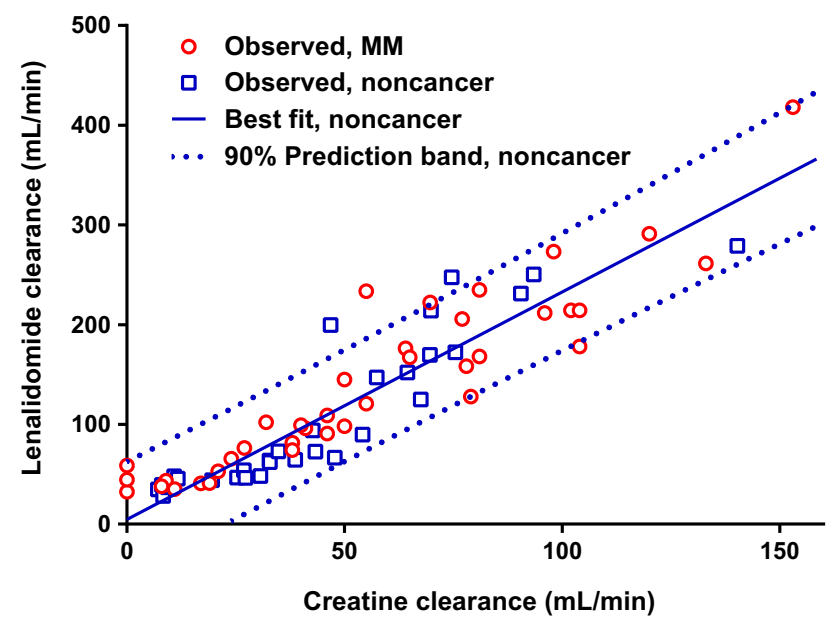

Fig. 2 Relationship between lenalidomide clearance and creatinine clearance. Creatinine clearance was estimated using the CockcroftGault formula. The solid line indicates the best fit line of linear regression, and the interval between the two dotted lines indicates the $90 \%$ prediction interval of the best fit line for patients without cancer. $M M$ multiple myeloma. Based on data from the literature reviewed in the text $[30,46]$

$5 \mathrm{mg}$ once daily for ESRD. The study showed a highly significant linear relationship between lenalidomide clearance and $\mathrm{CrCl}$ in patients with $\mathrm{MM}$ [46]. This relationship was almost identical to that observed in patients with RI due to non-malignant conditions (Fig. 2). Thus, MM disease itself does not affect the relationship between lenalidomide clearance (or plasma exposure) and renal function [46]. The mean AUC of each renal function group was within $\pm 25 \%$ of the mean AUC at the maximum tolerated dose [30], suggesting that the starting doses achieved the appropriate plasma exposure. Moreover, similar safety and efficacy were observed across the renal function groups.

In agreement with the results above, a population pharmacokinetic analysis showed that renal function was the only clinically important intrinsic factor affecting lenalidomide clearance, explaining $55 \%$ of the interindividual variability [39]. There was no difference in lenalidomide clearance among patients with MM, MDS, and MCL, suggesting that the same starting dose adjustment ratio can be applied to all approved hematologic indications.

\subsection{Patients with Hepatic Impairment}

No formal studies have been conducted to assess the effect of hepatic impairment on lenalidomide pharmacokinetics. Since lenalidomide is minimally metabolized in liver, lenalidomide plasma exposure is not anticipated to be changed in patients with compromised liver function. In the population pharmacokinetic analysis described above, mild hepatic impairment $(N=16)$ did not influence lenalidomide clearance [39].

\subsection{Pediatric Patients}

The pharmacokinetics of lenalidomide have been evaluated in pediatric patients with solid tumors in two phase I studies $[47,48]$, including a total of 47 pediatric patients aged $1-21$ years. Doses studied were $15-116 \mathrm{mg} / \mathrm{m}^{2} /$ day for children with brain tumors [48], and $15-70 \mathrm{mg} / \mathrm{m}^{2} /$ day for children with other solid tumors [47]. Overall, there was no large difference in pharmacokinetics between pediatric (all ages combined) and adult patients (Table 3). The half-life of lenalidomide was approximately $3 \mathrm{~h}$ in pediatric patients $[47,48]$, which is similar to that observed in adult patients with solid tumors $[49,50]$. The maximum tolerated dose was not defined in the two pediatric studies because all doses evaluated were well tolerated during the dose-finding period.

A comparison of lenalidomide clearance among pediatric age groups showed that the body surface area-adjusted lenalidomide clearance was significantly higher in children $5-11$ years of age $\left(160 \pm 40 \mathrm{~mL} / \mathrm{min} / \mathrm{m}^{2}\right)$ than in groups 12-17 years of age $\left(120 \pm 40 \mathrm{~mL} / \mathrm{min} / \mathrm{m}^{2}\right)$ or $18-21$ years of age $\left(105 \pm 40 \mathrm{~mL} / \mathrm{min} / \mathrm{m}^{2}\right)$ [47]. Thus, the body surface area-based dose may lead to lower lenalidomide AUC in children 5-11 years of age. Little pharmacokinetic information is available for children younger than 5 years of age. Because renal function reaches the adult level by 2 years of age [51], lenalidomide clearance in children $\geq 2$ years of age is not anticipated to be highly different from that in adults.

\subsection{Ethnic Groups}

A low sensitivity to ethnic factors has been demonstrated for lenalidomide pharmacokinetics. In a comparative pharmacokinetic study, $C_{\max }$ and AUC increased in a doseproportional manner $(5-20 \mathrm{mg})$ similarly for healthy Caucasian and Japanese volunteers, and the enantiomeric ratio of lenalidomide in plasma was nearly identical between the two ethnic groups [27]. Lenalidomide plasma exposure was also confirmed to be similar between Caucasian and Asian patients (Table 2), even though Asian patients usually had a lower body weight [36]. Together these findings demonstrate that no dose adjustment of lenalidomide is necessary when Asian patients are treated.

\section{Pharmacodynamics and Exposure Response}

\subsection{Effect on Cardiac Repolarization}

An assessment of the effect of lenalidomide on corrected QT (QTc) intervals was conducted in healthy males who each received a single oral dose of $10 \mathrm{mg}$ lenalidomide, 
Table 3 Comparison of lenalidomide pharmacokinetics between adult and pediatric patients with solid tumors

\begin{tabular}{|c|c|c|c|c|}
\hline & \multicolumn{2}{|l|}{ Solid tumors } & \multicolumn{2}{|c|}{ Central nervous system tumors } \\
\hline & Adults & Pediatric & Adults & Pediatric $^{\mathrm{a}}$ \\
\hline Dose range & $5-40 \mathrm{mg}$ & $5-70 \mathrm{mg} / \mathrm{m}^{2}$ & $2.5-20 \mathrm{mg} / \mathrm{m}^{2}$ & $20-116 \mathrm{mg} / \mathrm{m}^{2}$ \\
\hline$N$ & 43 & 29 & 24 & 18 \\
\hline Age (years) & $68(24-89)$ & $16(1-21)$ & $48(20-82)$ & $10(3-22)$ \\
\hline$T_{\max }(\mathrm{h})$ & $0.75-2$ & $0.5-1.5$ & $0.5-1.5$ & $2-4$ \\
\hline $\mathrm{CL} / F\left(\mathrm{~mL} / \mathrm{min} / \mathrm{m}^{2}\right)$ & $68-224^{\mathrm{b}}$ & $100-202$ & $169-451$ & $122-234$ \\
\hline$V_{\mathrm{z}} / F\left(\mathrm{~L} / \mathrm{m}^{2}\right)$ & $33.5-63^{\mathrm{b}}$ & $21-31$ & 39-90 & $27.4-60^{\mathrm{c}}$ \\
\hline$t_{1 / 2}(\mathrm{~h})$ & $2.7-6.7$ & $1.4-3.1$ & $2.2-5.6$ & $2.6-3.3$ \\
\hline References & [50] & [47] & [49] & [48] \\
\hline
\end{tabular}

Data are expressed as median (range) for age and arithmetic mean for pharmacokinetic parameters, unless otherwise stated

$C L / F$ apparent total clearance, $t_{1 / 2}$ terminal half-life, $T_{\max }$ time to reach the maximum concentration, $V_{\mathrm{z}} / F$ apparent volume of distribution based on the terminal phase

a Pharmacokinetic parameters are expressed as median values. Cohorts with a sample size $<3$ are combined to obtain the median value

b Assume a body surface area of $1.73 \mathrm{~m}^{2}$ for adult patients

${ }^{c}$ Derived from CL/F and $t_{1 / 2}$
$50 \mathrm{mg}$ lenalidomide, $400 \mathrm{mg}$ moxifloxacin (positive control), and placebo, in a randomized order [29]. Moxifloxacin significantly prolonged QTc, as expected. For lenalidomide 10 and $50 \mathrm{mg}$, the time-matched changes from placebo in the baseline-adjusted least-squares mean QTc were $<3 \mathrm{~ms}$, and the upper limit of the two-sided $90 \%$ CI for the change at all timepoints was $<10 \mathrm{~ms}$. After lenalidomide administration, no subject experienced a change from baseline $>60 \mathrm{~ms}$ or QTc $>450 \mathrm{~ms}$. Due to these outcomes, the study met the International Conference on Harmonisation (ICH) E14 definition of a negative thorough QT study.

Lenalidomide concentrations up to $1522 \mathrm{ng} / \mathrm{mL}$ were not significantly associated with QTc changes [29]. The lenalidomide concentration range observed in the QT study was close to that observed in patients receiving lenalidomide doses up to $50 \mathrm{mg}$, including those with reduced drug clearance associated with RI. Thus, lenalidomide is not expected to prolong QTc intervals in patients receiving therapeutic doses.

\subsection{Exposure Response}

The relationship between lenalidomide plasma exposure and hematologic toxicities was first explored in patients with transfusion-dependent MDS who were treated with lenalidomide at $10 \mathrm{mg}$ once daily [37]. Lenalidomide AUC was significantly higher in patients who had a $50 \%$ reduction in neutrophil or platelet counts, and in patients who developed grade 3/4 neutropenia or thrombocytopenia within the first 28 days. Similar relationships were observed with $C_{\max }$, but to a lesser degree. In addition, patients with deletion 5q MDS had a greater decrease in platelet and neutrophil counts than those without deletion $5 \mathrm{q}$, even though there was no difference in lenalidomide exposure between the two groups.

Subsequently, the relationship between lenalidomide AUC and grade 3/4 neutropenia or thrombocytopenia was examined in a meta-analysis including patients with MM, MDS, or MCL from six clinical studies over the dose range 5-50 mg [39]. After adjusting for disease and baseline cell counts, and including all treatment cycles up to 1 year, lenalidomide AUC was a significant predictor of grade 3/4 thrombocytopenia (odds ratio [OR] 3.337, $95 \%$ CI 1.183-9.415) and was also associated with increased grade 3/4 neutropenia (OR 1.978, $95 \%$ CI 0.999-3.917). These relationships were not apparent during the first treatment cycle.

Furthermore, the impact of $C_{\max }$ on safety and efficacy was examined using data collected from patients with MM and various degrees of renal function at the recommended starting doses (5-25 mg) [46]. Because RI mainly increases AUC with limited effect on $C_{\max }$ [30], a reduction in lenalidomide starting dose to match AUC led to lower $C_{\text {max }}$, especially in patients with moderate RI and ESRD in whom the dose was reduced by $60-80 \%$ [46]. As such, $C_{\text {max }}$ varied in a wider range than AUC in this study. However, no apparent pattern was observed between lenalidomide $C_{\max }$ and the grade of hematologic AEs or efficacy [46]. These data suggest that a high $C_{\max }$ is not critical for efficacy and support the AUC-matched dose adjustment for patients with RI. 


\section{Drug-Drug Interactions}

\subsection{Metabolism-Based Drug-Drug Interactions}

\subsubsection{Potential of Drug-Drug Interactions via Metabolic Pathways}

Phase I or II metabolism did not occur when lenalidomide was incubated with human liver microsomes, recombinant CYP isozymes, and human hepatocytes [32]. Lenalidomide, at concentrations $(\geq 10 \mu \mathrm{M})$ far exceeding the therapeutic $C_{\max }$ (often $<2 \mu \mathrm{M}$ [30]), did not inhibit CYP isozymes (1A2, 2C9, 2C19, 2E1, 2D6, 3A4/5) in human liver microsomes and did not induce activity of CYP isozymes (1A2, 2B6, 2C9, 2C19, 3A4/5) in cultured human hepatocytes [32]. Hence, lenalidomide is not anticipated to be subjected to pharmacokinetic drug-drug interactions when coadministered with CYP inhibitors, inducers, or substrates.

In a separate study, lenalidomide up to $50 \mu \mathrm{M}$ did not inhibit bilirubin glucuronidation in human liver microsomes with uridine diphosphate glucuronosyltransferase 1A1 (UGT1A1) genotyped as UGT1A $1 * 1 / * 1$, UGT1A $1 * 1 /$ *28, and UGT1A1*28/*28 [52]. As such, UGT1A1 inhibition and impairment of bilirubin conjugation may not be the mechanism of the reported hyperbilirubinemia in patients receiving lenalidomide $[52,53]$.

\subsubsection{Dexamethasone}

In patients with $\mathrm{MM}$ receiving lenalidomide/dexamethasone combination therapy, dexamethasone is administered at $40 \mathrm{mg}$ either weekly or more frequently (days 1-4, 9-12, and 17-20 of a 28-day cycle) [23]. Dexamethasone is a substrate and a weak-to-moderate inducer of CYP3A4 $[54,55]$. Results from three within-patient comparison studies demonstrated that dexamethasone has no effect on lenalidomide pharmacokinetics. In the first study [35], plasma exposure to lenalidomide $(25 \mathrm{mg})$ on day 12 after multiple coadministrations of dexamethasone $(40 \mathrm{mg} /$ day on days 3-4 and 9-12) was similar to that observed on day 1 after lenalidomide alone, but the sample size was smaller $(N=6)$. A second study [36] included more patients $(N=11)$ and compared lenalidomide pharmacokinetics at steady state with and without dexamethasone (40 mg). The $90 \% \mathrm{CI}$ for the ratio of treatment mean AUC or $C_{\max }$ was within the 80-125\% range (Fig. 3a), confirming the absence of a clinically significant dexamethasone effect. A third study was conducted in patients with RI [46], and no difference was found in mean lenalidomide plasma concentrations at $2 \mathrm{~h}$ postdose (near $T_{\max }$ ) between the days with or without $40 \mathrm{mg}$ dexamethasone across the renal function groups.

Dexamethasone is known to induce CYP3A4 activity at high doses [55], thereby accelerating its own metabolism. This may explain a slight reduction in dexamethasone plasma AUC (-24\%) upon coadministration of lenalidomide with frequent high doses of dexamethasone [35].

\subsubsection{Enzyme-Inducing Antiepileptic Drugs}

In patients with recurrent primary CNS tumors, enzymeinducing antiepileptic drugs-known to induce CYP enzymes such as CYP3A4-did not have any evident effect on lenalidomide exposure [49].

\subsubsection{Warfarin}

Warfarin is an anticoagulant and is metabolized primarily by CYP2C9, with some contribution from CYP2C19 and CYP3A4 [56]. Patients with MM receiving lenalidomide plus dexamethasone have an increased risk of venous
Fig. 3 a Effect of food and interacting drugs on plasma exposure to lenalidomide, and b effect of lenalidomide on plasma exposure to interacting drugs. Circles represent $\mathrm{AUC}_{\mathrm{t}}$, and squares represent $C_{\text {max }}$. Horizontal bars represent $90 \%$ $\mathrm{CI}$ for the percentage treatment ratio. $A U C_{t}$ area under the concentration-time curve from time zero to the last quantifiable concentration, $C_{\max }$ maximum concentration, $C I$ confidence interval. Based on data from the literature reviewed in the text [27, 33, 36, 59]
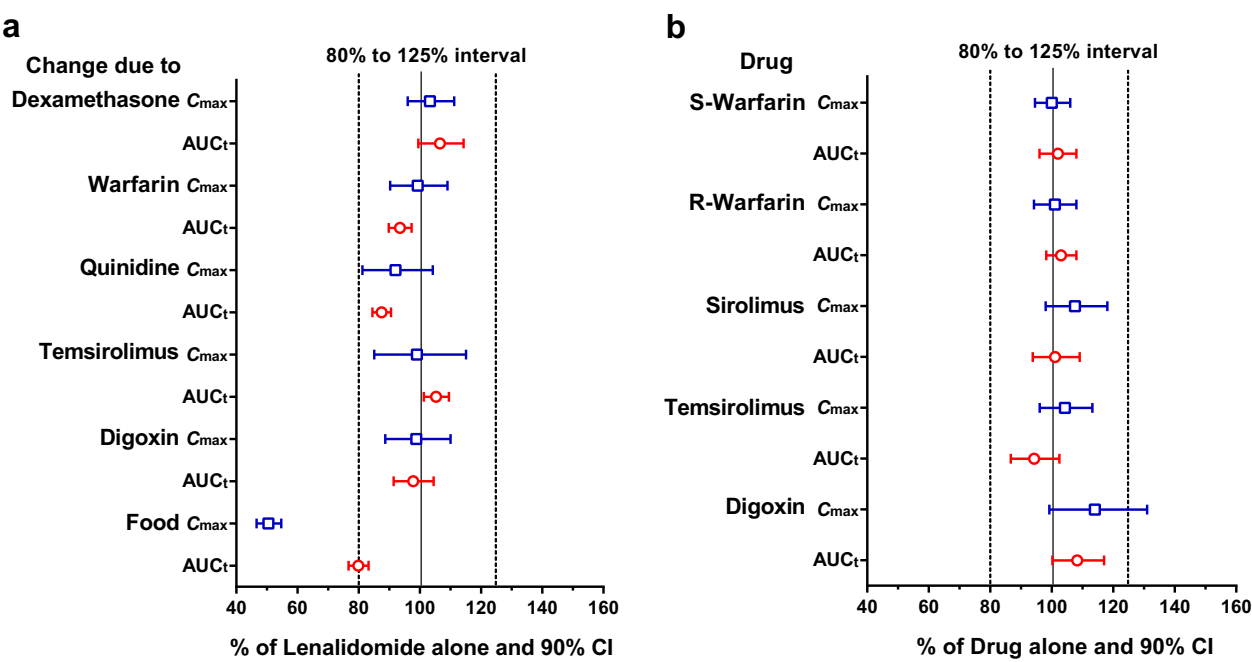
thromboembolism; thus, antithrombotic prophylaxis is recommended [22, 57]. Because of the prophylactic use of warfarin, a drug with a narrow therapeutic index [58], in patients with MM treated with lenalidomide, a doubleblind, placebo-controlled, randomized, crossover study was conducted in healthy volunteers to evaluate the pharmacokinetic and pharmacodynamic interactions between lenalidomide and warfarin [59]. In this study, coadministration of lenalidomide $(10 \mathrm{mg})$ with warfarin $(25 \mathrm{mg})$ did not alter the plasma exposure to warfarin or lenalidomide (Fig. 3). The effect of warfarin on prothrombin time and international normalized ratio was also unchanged by coadministration of lenalidomide. These data suggest that warfarin and lenalidomide can be coadministered without dose adjustments.

\subsection{Transporter-Based Drug-Drug Interactions}

\subsubsection{Potential of Drug-Drug Interactions via Transport Pathways}

In cells or vesicles expressing human transporters, lenalidomide was not a substrate of human breast cancer resistance protein (BCRP); multidrug resistance protein (MRP) transporter 1, MRP2, or MRP3; organic anion transporters (OAT) 1 and OAT3; organic anion transporting polypeptide (OATP) 1B1; organic cation transporters (OCT) 1 and OCT2; multidrug and toxin extrusion protein 1; and OCT novel (OCTN) 1 and OCTN2 [52]. Lenalidomide, at a concentration $\geq 20 \mu \mathrm{M}$, did not inhibit transporting activities of human BCRP, MRP2, OAT1, OAT3, OATP1B1, OATP1B3, OCT2, or bile-salt export pump [52]. Hence, lenalidomide is not anticipated to be subjected to pharmacokinetic drug-drug interactions when coadministered with substrates and/or inhibitors of these transporters.

In monolayers of LLC-PK1 and MDCKII cell lines expressing human P-glycoprotein (P-gp), lenalidomide was shown to be transported with average efflux ratios of 3 and 3.66 , respectively $[52,60]$. The P-gp-mediated lenalidomide transport was concentration dependent, with a Michaelis-Menten constant $\left(K_{\mathrm{m}}\right)$ value of $802 \pm 172 \mu \mathrm{M}$ [52]. The low efflux ratio and high $K_{\mathrm{m}}$ value suggest that lenalidomide is a weak P-gp substrate with low affinity for P-gp. However, lenalidomide did not inhibit the P-gp-dependent transport of digoxin at concentrations up to $300 \mu \mathrm{M}$ [52]. From these findings, the potential of lenalidomide interactions with P-gp substrates or inhibitors is considered low.

\subsubsection{P-Glycoprotein Inhibitors and/or Substrates}

P-gp is extensively expressed in the luminal membrane of the small intestine, where it pumps drugs back into the intestinal lumen, and in the apical membrane of the kidney proximal tubules, where it pumps drugs from tubule cells into the tubular lumen [61]. Since lenalidomide is a weak substrate of P-gp, P-gp inhibition could theoretically affect oral absorption and renal excretion of lenalidomide. As such, P-gp-based drug-drug interactions were suspected to be a potential mechanism for increased lenalidomide exposure upon coadministration of drugs interacting with P-gp in patients with MM [60, 62, 63]. In an uncontrolled dose-ranging study, mean $C_{\max }$ and AUC of lenalidomide $(25 \mathrm{mg} /$ day $)$ were doubled with a dose increase of the P-gp inhibitor/substrate temsirolimus from 15 to $20 \mathrm{mg}$ /day, while similar increases in $C_{\max }$ and AUC of temsirolimus $(15 \mathrm{mg} /$ day $)$ were also observed with a dose increase of lenalidomide from 20 to $25 \mathrm{mg} / \mathrm{day}$ [60]. In a within-patient comparison study, an increase in mean lenalidomide blood concentration was observed at $2-4 \mathrm{~h}$ postdose when lenalidomide $(15 \mathrm{mg} /$ day) was coadministered with the P-gp inhibitor clarithromycin (400 mg twice daily) [62]. In a case report, the lenalidomide AUC was 12-fold higher in an MM patient receiving both lenalidomide $(10 \mathrm{mg} /$ day $)$ and the P-gp inhibitor itraconazole (100 mg/day) compared with the AUC observed in other patients with MM receiving lenalidomide $(25 \mathrm{mg} /$ day $)$ alone [63]. Investigators in these studies suspected that oral absorption and/or renal excretion of lenalidomide (and temsirolimus) could be affected by drug interactions at the P-gp level $[60,62,63]$. However, none of the three studies showed a prolongation of drug half-life by the coadministration, and clarithromycin did not increase trough concentration and AUC of lenalidomide [62], which provides evidence against an effect on drug elimination (i.e. renal excretion). Lenalidomide is known to have high bioavailability (>90\%), which leaves little room (10\%) to increase oral absorption by P-gp inhibition.

The results from the above studies were likely confounded by a lack of control [60], small sample size $[60,63]$, multiple comorbidities, use of multiple concomitant medications, and other factors (e.g. food effect, bioanalytical assay). Hence, controlled crossover clinical studies [33] were conducted in healthy volunteers to definitively evaluate pharmacokinetic interactions between lenalidomide and three P-gp probe drugs, including the prototypical P-gp substrate digoxin [64], the well-characterized strong in vivo P-gp inhibitor quinidine [64], and the P-gp inhibitor/substrate temsirolimus. In these studies, digoxin $(0.5 \mathrm{mg}$, single dose), quinidine (300-600 mg twice daily for 5 days), or temsirolimus ( $25 \mathrm{mg}$, single dose) had no effect on lenalidomide pharmacokinetics. Mean treatment ratios and their $90 \%$ CIs for $C_{\max }$ and AUC of lenalidomide all fell entirely within the conventional bioequivalence range of $80-125 \%$ (Fig. 3a). The rate and capacity of lenalidomide renal excretion was not 
Table 4 Recommendations for the starting lenalidomide dose in patients with impaired renal function

\begin{tabular}{lll}
\hline Renal function $(\mathrm{CrCl})$ & Full starting dose $25 \mathrm{mg}$ & Full starting dose $10 \mathrm{mg}$ \\
\hline $\begin{array}{l}\text { Moderate renal impairment }(\mathrm{CrCl}=30 \text { to } \\
<50 \mathrm{~mL} / \mathrm{min})\end{array}$ & $10 \mathrm{mg}$ once daily & $5 \mathrm{mg}$ once daily \\
$\begin{array}{l}\text { Severe renal impairment }(\mathrm{CrCl}<30 \mathrm{~mL} / \mathrm{min}, \\
\text { not requiring dialysis })\end{array}$ & $\begin{array}{c}15 \mathrm{mg} \text { once every other day or } 7.5 \mathrm{mg} \text { once } \\
\text { daily }\end{array}$ & $5 \mathrm{mg}$ once every other day or $2.5 \mathrm{mg}$ daily \\
$\begin{array}{l}\text { End-stage renal disease }(\mathrm{CrCl}<30 \mathrm{~mL} / \mathrm{min}, \\
\text { requiring dialysis })\end{array}$ & $\begin{array}{l}5 \mathrm{mg} \text { once daily } \\
\text { On dialysis days, the dose should be } \\
\text { administered following dialysis }\end{array}$ & $\begin{array}{c}5 \mathrm{mg} \text { three times a week or } 2.5 \mathrm{mg} \text { daily } \\
\text { Ondalysis days, the dose should be } \\
\text { administered following dialysis }\end{array}$ \\
\hline
\end{tabular}

$\mathrm{CrCl}$ creatinine clearance

a The dose may be escalated to $15 \mathrm{mg}$ once daily after two cycles if the patient is not responding to treatment and is tolerating the drug

${ }^{\mathrm{b}}$ In countries where the 2.5 - and/or 7.5-mg capsule strengths are available

changed by quinidine or temsirolimus [33]. Oral absorption of lenalidomide was also not altered by quinidine or temsirolimus, judged from no change in $T_{\max }, C_{\max }$, and the amount of lenalidomide excreted in urine. On the other hand, lenalidomide had no effect on blood $C_{\max }$ and AUC of temsirolimus and its active metabolite sirolimus (also a P-gp inhibitor/substrate) [Fig. 3b]. When administered with lenalidomide versus placebo, the $C_{\max }$ of digoxin was slightly higher $(+14 \%)$, but there were no other effects on digoxin pharmacokinetics [33]. From the controlled studies, it was concluded that no clinically significant pharmacokinetic interactions exist between lenalidomide and a P-gp inhibitor or substrate.

\section{Discussion}

The clinical pharmacokinetics of lenalidomide are characterized by rapid absorption with high oral bioavailability, a dose-proportional increase in plasma exposure, low protein binding, distribution into semen, minimum metabolism, rapid elimination predominantly through urinary excretion of the unchanged drug, and low ethnic sensitivity. Lenalidomide does not prolong QT interval at a dose twice the approved maximum dose. Higher plasma exposure to lenalidomide is associated with an increased risk of neutropenia and thrombocytopenia. However, the increased plasma exposure to lenalidomide in patients versus young, healthy volunteers is considered clinically irrelevant because the therapeutic doses are established based on safety and efficacy data from these patients.

Coadministration with food reduces the extent and rate of lenalidomide absorption. The reductions in AUC ($20 \%)$ and $C_{\max }(-50 \%)$ are considered clinically insignificant because the concentration fluctuation during typical lenalidomide treatment (e.g. following dose reductions due to AEs) often has a similar or greater effect on lenalidomide plasma exposure compared with the food effect. Importantly, the safety and efficacy of lenalidomide were established in registration trials in which the drug was administered without any specific instructions regarding food intake [8-13]. Therefore, lenalidomide can be administered with or without food. However, the food-induced reduction in lenalidomide $C_{\max }$ may confound pharmacokinetic data interpretation. Thus, it is preferred to control food intake for pharmacokinetic evaluations, especially for drug-drug interaction studies.

Since it is not a substrate, inhibitor, and/or inducer of major human metabolic enzymes or transporters [32, 52], lenalidomide has a low potential for pharmacokinetic drug interactions. Although conflicting results were reported, no clinically significant pharmacokinetic interactions between lenalidomide and P-gp substrates/inhibitors were observed in well-controlled studies [33]. Therefore, lenalidomide can be coadministered with a P-gp inhibitor or substrate without dose adjustment. It should be noted that the underlying mechanism for a $14 \%$ increase in digoxin $C_{\max }$ upon coadministration of lenalidomide cannot be explained by direct inhibition of P-gp because lenalidomide does not inhibit P-gp-dependent transport of digoxin in vitro [52]. To date, there has been no evidence in the literature of any significant toxicity due to concomitant use of lenalidomide and digoxin. Because digoxin has a narrow therapeutic window, periodic monitoring of digoxin concentration is recommended during lenalidomide therapy.

The most important factor increasing lenalidomide plasma exposure is RI [30]. A general guideline of starting dose adjustments has been developed for patients with $\mathrm{CrCl}<50 \mathrm{~mL} / \mathrm{min}$ (Table 4 ) based on increased AUC by RI, pharmacokinetic similarity across patient populations, availability of the lenalidomide dosage strengths, dose response for efficacy, and patients' tolerability. The $50 \mathrm{~mL} / \mathrm{min} \mathrm{CrCl}$ cutoff was chosen because it was used as the lower limit for mild $\mathrm{RI}(\mathrm{CrCl} 50-80 \mathrm{~mL} / \mathrm{min})$ in two definitive renal studies, and the increase in plasma exposure with mild RI was modest $[30,46]$. Furthermore, the full starting dose was well tolerated in patients with mild RI in clinical studies [46, 65, 66]. Hemodialysis accelerates 


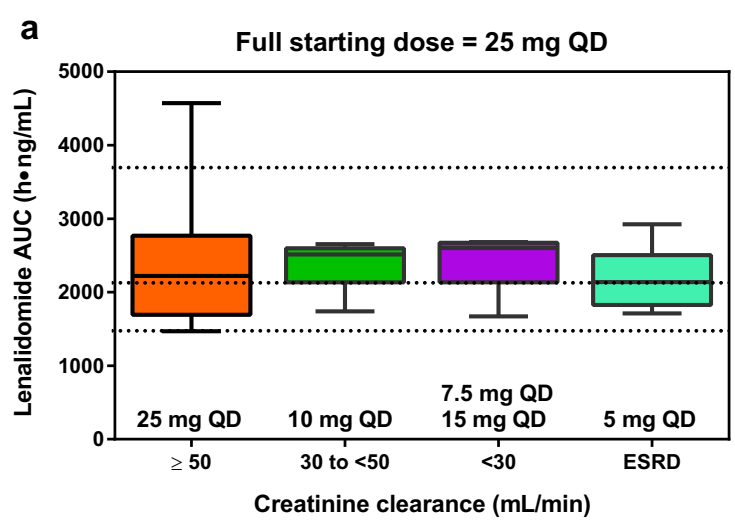

C

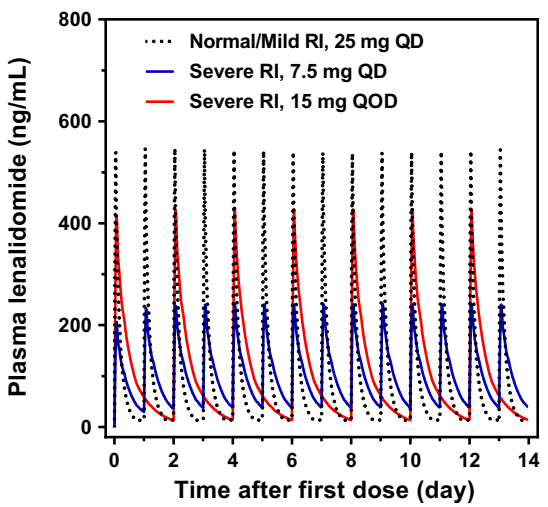

b

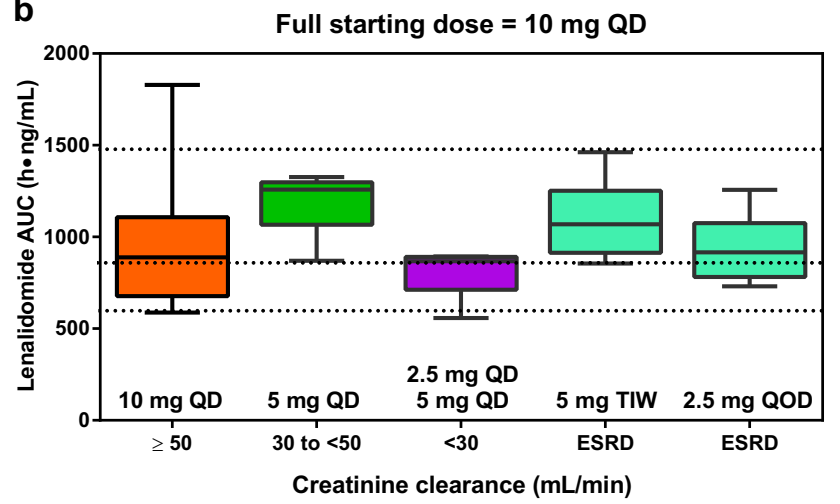

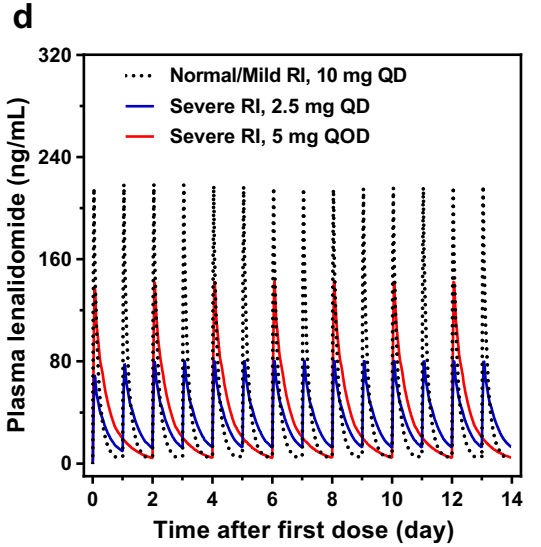

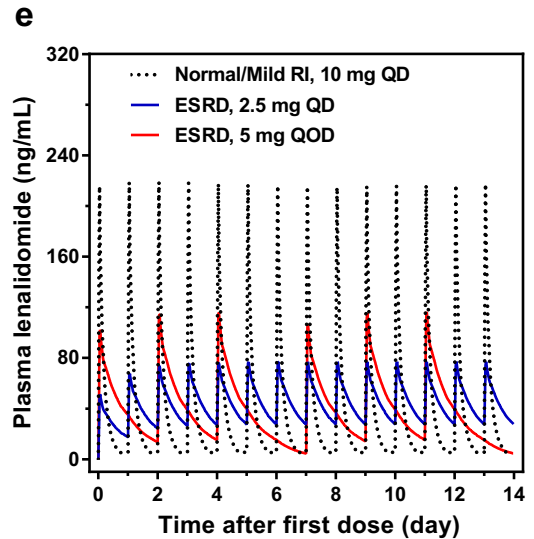

Fig. 4 Predicted lenalidomide plasma exposure at steady state in patients with RI. a Predicted average daily AUC at recommended starting doses when the full starting dose is $25 \mathrm{mg}$ for patients with creatinine clearance $\geq 50 \mathrm{~mL}$. b Predicted AUC at recommended starting doses when the full starting dose is $10 \mathrm{mg}$ for patients with creatinine clearance $\geq 50 \mathrm{~mL}$. c-e Comparison of predicted lenalidomide plasma concentration profiles among QD, QOD, and TIW dosing schedules in patients with severe RI or ESRD. In $\mathbf{a}, \mathbf{b}$, the horizontal dotted lines represent the 5th, 50th, and 95th percentiles of

lenalidomide removal from the body [30]. Thus, in patients with ESRD, the reduced dose should be administered immediately following completion of each dialysis session to minimize the effect of hemodialysis on lenalidomide clearance.

The aim of dose adjustment in patients with $\mathrm{CrCl}<50 \mathrm{~mL} / \mathrm{min}$ is to achieve an initial AUC that would be efficacious with a manageable $\mathrm{AE}$ profile, i.e. close to the AUC range after administration of the full starting dose to patients with $\mathrm{CrCl} \geq 50 \mathrm{~mL} / \mathrm{min}$. Simulation results suggest that the steady-state daily AUC at the reduced starting dose for patients with moderate or worse RI is comparable with that at the full starting dose for patients with $\mathrm{CrCl} \geq 50 \mathrm{~mL} / \mathrm{min} \quad$ (Fig. $4 \mathrm{a}, \quad$ b). Because early lenalidomide dose intensity is considered crucial for optimal outcomes [67], a modestly high starting AUC is preferred over a lower AUC when a desirable AUC match is not feasible. Depending on indication and the availability
AUC observed in target patient populations, the box plots represent AUC predicted for each renal function group based on data from noncancer patients [30], the white line in each box represents the mean, the height of each box corresponds to the interval between the first and third quartiles, and the horizontal lines at two ends of each box correspond to the range, from minimum to maximum. RI renal impairment, $A U C$ area under the concentration-time curve, $Q D$ once daily, $Q O D$ once every other day, $T I W$ three times a week, $E S R D$ endstage renal disease. Data on file at Celgene

of capsule strengths, there are two dosing schedules for the reduced starting dose in patients with severe RI or ESRD: once daily with lower capsule strengths, or less frequent dosing (once every other day or three times a week) with higher capsule strengths. The average daily AUC is predicted to be similar for the two schedules (Fig. 4a, b). Compared with the once every other day or three times a week regimen, the once daily regimen would reduce the fluctuation of lenalidomide plasma level (Fig. 4c-e) and the individual body load of each single dose, which may reduce toxicity. The once daily regimen may also improve patient compliance in terms of allowing for daily dosing where appropriate.

Lenalidomide has a short half-life and rarely accumulates in plasma under a daily dosing schedule. The $88 \%$ recovery of total radioactivity of $\left[{ }^{14} \mathrm{C}\right]$-lenalidomide from excreta within $24 \mathrm{~h}$ [28] suggests little tissue retention of lenalidomide and its metabolites. Thus, most lenalidomide 
toxicities can be managed effectively by dose reductions and interruptions in subsequent treatment cycles if the patient does not tolerate the starting dose.

\section{Conclusions}

The studies discussed in this review provide the pharmacokinetic and pharmacodynamic basis for safe and effective use of lenalidomide in the clinic. Renal function is the most important factor affecting lenalidomide plasma exposure in humans, and AUC-matched dose adjustments are recommended for patients with $\mathrm{CrCl}<50 \mathrm{~mL} / \mathrm{min}$ at the start of therapy. Lenalidomide toxicities can be further controlled by step-down dose reductions/interruptions. No dose adjustment for lenalidomide is warranted on the basis of age, ethnicity, mild hepatic impairment, or drug-drug interactions.

Acknowledgments The authors thank Stephanie Morgan, $\mathrm{PhD}$, of MediTech Media for medical writing assistance sponsored by Celgene Corporation.

\section{Compliance with Ethical Standards}

Funding Support for this study and preparation of this manuscript was provided by Celgene Corporation.

Conflicts of interest Nianhang Chen, Simon Zhou, and Maria Palmisano are full-time employees of Celgene Corporation and own stock in the company.

Open Access This article is distributed under the terms of the Creative Commons Attribution-NonCommercial 4.0 International License (http://creativecommons.org/licenses/by-nc/4.0/), which permits any noncommercial use, distribution, and reproduction in any medium, provided you give appropriate credit to the original author(s) and the source, provide a link to the Creative Commons license, and indicate if changes were made.

\section{References}

1. Heise C, Carter T, Schafer P, Chopra R. Pleiotropic mechanisms of action of lenalidomide efficacy in $\operatorname{del}(5 \mathrm{q})$ myelodysplastic syndromes. Expert Rev Anticancer Ther. 2010;10:1663-72.

2. Zeldis JB, Knight R, Hussein M, Chopra R, Muller G. A review of the history, properties, and use of the immunomodulatory compound lenalidomide. Ann N Y Acad Sci. 2011;1222:76-82.

3. Zhu YX, Kortuem KM, Stewart AK. Molecular mechanism of action of immune-modulatory drugs thalidomide, lenalidomide and pomalidomide in multiple myeloma. Leuk Lymphoma. 2013;54:683-7.

4. Zhu YX, Braggio E, Shi CX, Bruins LA, Schmidt JE, Van Wier S, et al. Cereblon expression is required for the antimyeloma activity of lenalidomide and pomalidomide. Blood. 2011;118:4771-9.

5. Lopez-Girona A, Mendy D, Ito T, Miller K, Gandhi AK, Kang J, et al. Cereblon is a direct protein target for immunomodulatory and antiproliferative activities of lenalidomide and pomalidomide. Leukemia. 2012;26:2326-35.
6. Gandhi AK, Kang J, Havens CG, Conklin T, Ning Y, Wu L, et al. Immunomodulatory agents lenalidomide and pomalidomide costimulate $\mathrm{T}$ cells by inducing degradation of $\mathrm{T}$ cell repressors Ikaros and Aiolos via modulation of the E3 ubiquitin ligase complex CRL4(CRBN). Br J Haematol. 2014;164:811-21.

7. Guirguis AA, Ebert BL. Lenalidomide: deciphering mechanisms of action in myeloma, myelodysplastic syndrome and beyond. Curr Opin Cell Biol. 2015;37:61-7.

8. List A, Dewald G, Bennett J, Giagounidis A, Raza A, Feldman E, et al. Lenalidomide in the myelodysplastic syndrome with chromosome 5q deletion. N Engl J Med. 2006;355:1456-65.

9. Dimopoulos M, Spencer A, Attal M, Prince HM, Harousseau JL, Dmoszynska A, et al. Lenalidomide plus dexamethasone for relapsed or refractory multiple myeloma. $\mathrm{N}$ Engl $\mathrm{J}$ Med. 2007;357:2123-32.

10. Weber DM, Chen C, Niesvizky R, Wang M, Belch A, Stadtmauer EA, et al. Lenalidomide plus dexamethasone for relapsed multiple myeloma in North America. N Engl J Med. 2007;357:2133-42.

11. Fenaux P, Giagounidis A, Selleslag D, Beyne-Rauzy O, Mufti G, Mittelman M, et al. A randomized phase 3 study of lenalidomide versus placebo in RBC transfusion-dependent patients with low-/ intermediate-1-risk myelodysplastic syndromes with del5q. Blood. 2011;118:3765-76.

12. Goy A, Sinha R, Williams ME, Kalayoglu Besisik S, Drach J, Ramchandren R, et al. Single-agent lenalidomide in patients with mantle-cell lymphoma who relapsed or progressed after or were refractory to bortezomib: phase II MCL-001 (EMERGE) study. J Clin Oncol. 2013;31:3688-95.

13. Benboubker L, Dimopoulos MA, Dispenzieri A, Catalano J, Belch AR, Cavo M, et al. Lenalidomide and dexamethasone in transplant-ineligible patients with myeloma. N Engl J Med. 2014;371:906-17.

14. Lonial S, Dimopoulos M, Palumbo A, White D, Grosicki S, Spicka I, et al. Elotuzumab therapy for relapsed or refractory multiple myeloma. N Engl J Med. 2015;373:621-31.

15. Stewart AK, Rajkumar SV, Dimopoulos MA, Masszi T, Spicka I, Oriol A, et al. Carfilzomib, lenalidomide, and dexamethasone for relapsed multiple myeloma. N Engl J Med. 2015;372:142-52.

16. Moreau P, Masszi T, Grzasko N, Bahlis NJ, Hansson M, Pour L, et al. Ixazomib, an investigational oral proteasome inhibitor, in combination with lenalidomide and dexamethasone, significantly extends progression-free survival for patients with relapsed and/ or refractory multiple myeloma: the phase 3 Tourmaline-MM1 study (NCT01564537) [oral presentation]. Blood. 2015;126:727.

17. Takeda Pharmaceutical Company Limited. Ninlaro ${ }^{\circledR}$ (ixazomib). Prescribing information. 2015. http://www.accessdata.fda.gov/ drugsatfda_docs/label/2015/208462lbl.pdf. Accessed 7 Mar 2016.

18. Bristol-Myers Squibb Company. Empliciti ${ }^{\mathrm{TM}}$ (elotuzumab). Prescribing information. 2015. http://packageinserts.bms.com/pi/ pi_empliciti.pdf. Accessed 7 Mar 2016.

19. Amgen Europe B.V. Kyprolis (carfilzomib). Summary of product characteristics. 2015. http://www.ema.europa.eu/docs/en_GB/ document_library/EPAR_-_Product_Information/human/003790/ WC500197692.pdf. Accessed 7 Mar 2016.

20. Amgen. Kyprolis ${ }^{\circledR}$ (carfilzomib). Prescribing information. 2015. http://pi.amgen.com/united_states/kyprolis/kyprolis_pi.pdf. Accessed 7 Mar 2016.

21. Blumel S, Broadway-Duren J. Approaches to managing safety with lenalidomide in hematologic malignancies. J Adv Pract Oncol. 2014;5:269-79.

22. Zagouri F, Terpos E, Kastritis E, Dimopoulos MA. An update on the use of lenalidomide for the treatment of multiple myeloma. Expert Opin Pharmacother. 2015;16:1865-77.

23. Celgene Corporation. Revlimid ${ }^{\circledR}$ (lenalidomide). Prescribing information. 2015. http://www.revlimid.com/wp-content/uploads/ 2013/11/PI.pdf. Accessed 6 Jan 2016. 
24. Ghosh N, Grunwald MR, Fasan O, Bhutani M. Expanding role of lenalidomide in hematologic malignancies. Cancer Manag Res. 2015;7:105-19.

25. Celgene Europe Limited. Revlimid ${ }^{\circledR}$ (lenalidomide). Summary of product characteristics. 2015. https://www.medicines.org.uk/emc/ medicine/29478. Accessed 22 Feb 2016.

26. Morita TO, Yamaguchi A, Kimura S, Fujii H, Endo K, Izumi K, et al. Stability of lenalidomide suspension after preparation by a simple suspension method for enteral tube administration. J Oncol Pharm Pract. 2015;. doi:10.1177/1078155215593623 (Epub 6 Jul 2015).

27. Chen N, Kasserra C, Reyes J, Liu L, Lau H. Single-dose pharmacokinetics of lenalidomide in healthy volunteers: dose proportionality, food effect, and racial sensitivity. Cancer Chemother Pharmacol. 2012;70:717-25.

28. Chen N, Wen L, Lau H, Surapaneni S, Kumar G. Pharmacokinetics, metabolism and excretion of $[(14) \mathrm{C}]$-lenalidomide following oral administration in healthy male subjects. Cancer Chemother Pharmacol. 2012;69:789-97.

29. Chen N, Ye Y, Liu L, Reyes J, Assaf MS, Kasserra C, et al. Lenalidomide at therapeutic and supratherapeutic doses does not prolong QTc intervals in the thorough QTc study conducted in healthy men. Basic Clin Pharmacol Toxicol. 2013;113:179-86.

30. Chen N, Lau H, Kong L, Kumar G, Zeldis JB, Knight R, et al. Pharmacokinetics of lenalidomide in subjects with various degrees of renal impairment and in subjects on hemodialysis. J Clin Pharmacol. 2007;47:1466-75.

31. Chen N, Lau H, Choudhury S, Wang X, Assaf M, Laskin OL. Distribution of lenalidomide into semen of healthy men after multiple oral doses. J Clin Pharmacol. 2010;50:767-74.

32. Kumar G, Lau H, Laskin O. Lenalidomide: in vitro evaluation of the metabolism and assessment of cytochrome P450 inhibition and induction. Cancer Chemother Pharmacol. 2009;63:1171-5.

33. Chen N, Weiss D, Reyes J, Liu L, Kasserra C, Wang X, et al. No clinically significant drug interactions between lenalidomide and P-glycoprotein substrates and inhibitors: results from controlled phase I studies in healthy volunteers. Cancer Chemother Pharmacol. 2014;74:659-60.

34. Richardson PG, Schlossman RL, Weller E, Hideshima T, Mitsiades C, Davies F, et al. Immunomodulatory drug CC-5013 overcomes drug resistance and is well tolerated in patients with relapsed multiple myeloma. Blood. 2002;100:3063-7.

35. Iida S, Chou T, Okamoto S, Nagai H, Hatake K, Murakami H, et al. Lenalidomide plus dexamethasone treatment in Japanese patients with relapsed/refractory multiple myeloma. Int $\mathrm{J}$ Hematol. 2010;92:118-26.

36. Hou J, Du X, Jin J, Cai Z, Chen F, Zhou DB, et al. A multicenter, open-label, phase 2 study of lenalidomide plus low-dose dexamethasone in Chinese patients with relapsed/refractory multiple myeloma: the MM-021 trial. J Hematol Oncol. 2013;6:41.

37. Komrokji RS, Lancet JE, Swern AS, Chen N, Paleveda J, Lush R, et al. Combined treatment with lenalidomide and epoetin alfa in lower-risk patients with myelodysplastic syndrome. Blood. 2012;120:3419-24.

38. Harada H, Watanabe M, Suzuki K, Yanagita S, Suzuki T, Yoshida Y, et al. Lenalidomide is active in Japanese patients with symptomatic anemia in low- or intermediate-1 risk myelodysplastic syndromes with a deletion $5 \mathrm{q}$ abnormality. Int J Hematol. 2009;90:353-60.

39. Chen N, Ette E, Zhou S, Weiss D, Palmisano M. Population pharmacokinetics and exposure-safety of lenalidomide in patients with multiple myeloma, myelodysplastic syndromes, and mantle cell lymphoma [poster presentation]. Blood. 2013;122:3234.

40. Wendtner C, Hallek M, Fraser G, Michallet A, Hillmen P, Duerig $\mathrm{J}$, et al. Dose-escalation and pharmacokinetics (PK) of different lenalidomide (Len) starting dose regimens in patients with relapsed or refractory (Rel/Ref) chronic lymphocytic leukemia (CLL) (CC-5013-CLL-009). Haematologica. 2013;98:41-2.

41. Blum W, Klisovic RB, Becker H, Yang X, Rozewski DM, Phelps MA, et al. Dose escalation of lenalidomide in relapsed or refractory acute leukemias. J Clin Oncol. 2010;28:4919-25.

42. Ogura M, Imaizumi Y, Uike N, Asou N, Utsunomiya A, Uchida $\mathrm{T}$, et al. Lenalidomide in relapsed adult T-cell leukaemia-lymphoma or peripheral T-cell lymphoma (ATLL-001): a phase 1, multicentre, dose-escalation study. Lancet Haematol. 2016;3(3):e107-18.

43. Anwer S, Collings F, Trace K, Sun Y, Sternberg A. Cerebrospinal fluid penetrance of lenalidomide in meningeal myeloma. $\mathrm{Br} \mathrm{J}$ Haematol. 2013;162:281-2.

44. Rubenstein JL, Formaker P, Wang X, Chen N, Seider M, Munster $\mathrm{P}$, et al. Interim results of a phase I study of lenalidomide (CC5013) plus intraventricular/intravenous rituximab for recurrent/ refractory CNS and intraocular lymphoma. Blood. 2014; $124: 4470$.

45. Dimopoulos MA, Terpos E, Chanan-Khan A, Leung N, Ludwig $\mathrm{H}$, Jagannath $\mathrm{S}$, et al. Renal impairment in patients with multiple myeloma: a consensus statement on behalf of the International Myeloma Working Group. J Clin Oncol. 2010;28:4976-84.

46. Bridoux F, Chen N, Moreau S, Arnulf B, Moumas E, Abraham J, et al. Pharmacokinetics, safety, and efficacy of lenalidomide plus dexamethasone in patients with multiple myeloma and renal impairment. Cancer Chemother Pharmacol. 2016. doi:10.1007/ s00280-016-3068-9 (Epub 10 June 2016).

47. Berg SL, Cairo MS, Russell H, Ayello J, Ingle AM, Lau H, et al. Safety, pharmacokinetics, and immunomodulatory effects of lenalidomide in children and adolescents with relapsed/refractory solid tumors or myelodysplastic syndrome: a Children's Oncology Group Phase I Consortium report. J Clin Oncol. 2011;29:316-23.

48. Warren KE, Goldman S, Pollack IF, Fangusaro J, Schaiquevich P, Stewart CF, et al. Phase I trial of lenalidomide in pediatric patients with recurrent, refractory, or progressive primary CNS tumors: Pediatric Brain Tumor Consortium study PBTC-018. J Clin Oncol. 2011;29:324-9.

49. Fine HA, Kim L, Albert PS, Duic JP, Ma H, Zhang W, et al. A phase I trial of lenalidomide in patients with recurrent primary central nervous system tumors. Clin Cancer Res. 2007;13:7101-6.

50. Dahut WL, Aragon-Ching JB, Woo S, Tohnya TM, Gulley JL, Arlen PM, et al. Phase I study of oral lenalidomide in patients with refractory metastatic cancer. J Clin Pharmacol. 2009;49:650-60.

51. Rodieux F, Wilbaux M, van den Anker JN, Pfister M. Effect of kidney function on drug kinetics and dosing in neonates, infants, and children. Clin Pharmacokinet. 2015;54:1183-204.

52. Tong Z, Yerramilli U, Surapaneni S, Kumar G. The interactions of lenalidomide with human uptake and efflux transporters and UDP-glucuronosyltransferase 1A1: lack of potential for drugdrug interactions. Cancer Chemother Pharmacol. 2014;73:869-74.

53. Simondsen KA, Kolesar JM. Lenalidomide-induced elevated bilirubin. J Oncol Pharm Pract. 2012;18:402-5.

54. Gentile DM, Tomlinson ES, Maggs JL, Park BK, Back DJ. Dexamethasone metabolism by human liver in vitro. Metabolite identification and inhibition of 6-hydroxylation. J Pharmacol Exp Ther. 1996;277:105-12.

55. McCune JS, Hawke RL, LeCluyse EL, Gillenwater HH, Hamilton $\mathrm{G}$, Ritchie J, et al. In vivo and in vitro induction of human cytochrome P4503A4 by dexamethasone. Clin Pharmacol Ther. 2000;68:356-66.

56. Ufer M. Comparative pharmacokinetics of vitamin K antagonists: warfarin, phenprocoumon and acenocoumarol. Clin Pharmacokinet. 2005;44:1227-46. 
57. Zamagni E, Brioli A, Tacchetti P, Zannetti B, Pantani L, Cavo M. Multiple myeloma, venous thromboembolism, and treatment-related risk of thrombosis. Semin Thromb Hemost. 2011;37:209-19.

58. Kimmel SE. Warfarin therapy: in need of improvement after all these years. Expert Opin Pharmacother. 2008;9:677-86.

59. Weiss D, Knight R, Zhou S, Palmisano M, Chen N. Evaluation of pharmacokinetic and pharmacodynamic interactions when lenalidomide is co-administered with warfarin in a randomized clinical trial setting. Clin Drug Investig. 2015;35:455-61.

60. Hofmeister CC, Yang X, Pichiorri F, Chen P, Rozewski DM, Johnson AJ, et al. Phase I trial of lenalidomide and CCI-779 in patients with relapsed multiple myeloma: evidence for lenalidomide-CCI-779 interaction via P-glycoprotein. J Clin Oncol. 2011;29:3427-34.

61. International Transporter Consortium, Giacomini KM, Huang SM, Tweedie DJ, Benet LZ, Brouwer KL, et al. Membrane transporters in drug development. Nat Rev Drug Discov. 2010;9:215-36.

62. Takezako N, Miura M, Nagata A, Sekiguchi N, Niioka T, Shida $\mathrm{S}$, et al. Clarithromycin elevates the plasma concentration of lenalidomide via inhibition of MDR1. Blood. 2014;124:3479.
63. Takahashi N, Miura M, Kameoka Y, Abumiya M, Sawada K. Drug interaction between lenalidomide and itraconazole. Am J Hematol. 2012;87:338-9.

64. Fenner KS, Troutman MD, Kempshall S, Cook JA, Ware JA, Smith DA, et al. Drug-drug interactions mediated through P-glycoprotein: clinical relevance and in vitro-in vivo correlation using digoxin as a probe drug. Clin Pharmacol Ther. 2009;85:173-81.

65. Klein U, Neben K, Hielscher T, Heiss C, Ho AD, Goldschmidt H. Lenalidomide in combination with dexamethasone: effective regimen in patients with relapsed or refractory multiple myeloma complicated by renal impairment. Ann Hematol. 2011;90:429-39.

66. Dimopoulos MA, Cheung MC, Roussel M, Liu T, Gamberi B, Kolb $\mathrm{B}$, et al. Impact of renal impairment on outcomes with lenalidomide and dexamethasone treatment in the FIRST trial, a randomized, open-label phase 3 trial in transplant-ineligible patients with multiple myeloma. Haematologica. 2016;101(3):363-70.

67. Komrokji RS, List AF. Short- and long-term benefits of lenalidomide treatment in patients with lower-risk del $(5 \mathrm{q})$ myelodysplastic syndromes. Ann Oncol. 2016;27:62-8. 